\title{
UNIVERSITYOF BIRMINGHAM

\section{Tribological performance of rice husk ceramic particles as a solid additive in liquid paraffin}

Hu, Enzhu; Hu, Kunhong; Dearn, Karl; Hu, Xianguo; Xu, Yufu; Yu, Dongrui; Gu, Huiming; Tang, Yuchao

DOI:

10.1016/j.triboint.2016.06.035

License:

Creative Commons: Attribution-NonCommercial-NoDerivs (CC BY-NC-ND)

\section{Document Version}

Peer reviewed version

Citation for published version (Harvard):

Hu, E, Hu, K, Dearn, K, Hu, X, Xu, Y, Yu, D, Gu, H \& Tang, Y 2016, 'Tribological performance of rice husk ceramic particles as a solid additive in liquid paraffin', Tribology International.

https://doi.org/10.1016/j.triboint.2016.06.035

Link to publication on Research at Birmingham portal

Publisher Rights Statement:

Checked 15/7/2016

\section{General rights}

Unless a licence is specified above, all rights (including copyright and moral rights) in this document are retained by the authors and/or the copyright holders. The express permission of the copyright holder must be obtained for any use of this material other than for purposes permitted by law.

-Users may freely distribute the URL that is used to identify this publication.

- Users may download and/or print one copy of the publication from the University of Birmingham research portal for the purpose of private study or non-commercial research.

-User may use extracts from the document in line with the concept of 'fair dealing' under the Copyright, Designs and Patents Act 1988 (?)

- Users may not further distribute the material nor use it for the purposes of commercial gain.

Where a licence is displayed above, please note the terms and conditions of the licence govern your use of this document.

When citing, please reference the published version.

Take down policy

While the University of Birmingham exercises care and attention in making items available there are rare occasions when an item has been uploaded in error or has been deemed to be commercially or otherwise sensitive.

If you believe that this is the case for this document, please contact UBIRA@lists.bham.ac.uk providing details and we will remove access to the work immediately and investigate. 


\section{Author's Accepted Manuscript}

Tribological performance of rice husk ceramic particles as a solid additive in liquid paraffin

Enzhu $\mathrm{Hu}$, Kunhong $\mathrm{Hu}$, Karl David Dearn, Xianguo Hu, Yufu Xu, Dongrui Yu, Huiming Gu, Yuchao Tang

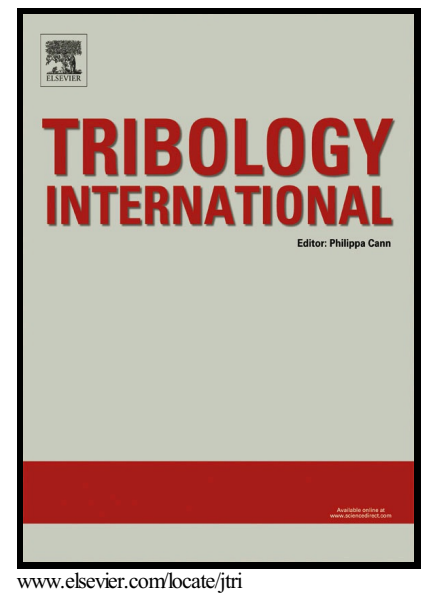

PII: $\quad$ S0301-679X(16)30205-5

DOI: $\quad$ http://dx.doi.org/10.1016/j.triboint.2016.06.035

Reference: JTRI4267

To appear in: Tribiology International

Received date: 28 January 2016

Revised date: 7 June 2016

Accepted date: 25 June 2016

Cite this article as: Enzhu Hu, Kunhong Hu, Karl David Dearn, Xianguo Hu Yufu Xu, Dongrui Yu, Huiming Gu and Yuchao Tang, Tribological performance of rice husk ceramic particles as a solid additive in liquid paraffin, Tribiolog. International, http://dx.doi.org/10.1016/j.triboint.2016.06.035

This is a PDF file of an unedited manuscript that has been accepted fo publication. As a service to our customers we are providing this early version o the manuscript. The manuscript will undergo copyediting, typesetting, an review of the resulting galley proof before it is published in its final citable form Please note that during the production process errors may be discovered whic could affect the content, and all legal disclaimers that apply to the journal pertain 


\section{Tribological Performance of Rice Husk Ceramic Particles as a \\ Solid Additive in Liquid Paraffin}

Enzhu $\mathrm{Hu}^{1 *}$, Kunhong $\mathrm{Hu}^{1}$, Karl David Dearn ${ }^{2}$, Xianguo $\mathrm{Hu}^{3}$, Yufu $\mathrm{Xu}^{3}$, Dongrui $\mathrm{Yu}^{3}$, Huiming $\mathrm{Gu}^{1}$, Yuchao Tang ${ }^{1}$

${ }^{1}$ Department of Chemical and Materials Engineering, Hefei University, 99 Jinxiu Road, Hefei 230601, PR. China

${ }^{2}$ Department of Mechanical Engineering, School of Engineering, University of Birmingham, Edgbaston,

Birmingham, B15 2TT, United Kingdom

${ }^{3}$ Institute of Tribology, Hefei University of Technology, 193 Tunxi Road, Hefei 230009, PR. China

huez@hfuu.edu.cn

huenzhu7@163.com

*Corresponding author: Tel.: +86 13956020635

\section{Abstract}

Rice husk ceramic (RHC) particles were prepared and its effect on the lubrication performance of liquid paraffin (LP) was investigated using a four-ball tribometer to expand the comprehensive utilization of rice husk. The wear and friction mechanisms of RHC particles were also investigated. Results showed that RHC particles can strengthen the antiwear and friction reduction properties of LP in the presence of $2 \mathrm{wt} \%$ polyisobutylene succinimide (T154A) at 75 or $100{ }^{\circ} \mathrm{C}$. The friction and wear mechanisms of RHC particles were ascribed to high temperature, which ensures the involvement of RHC particles in the formation of boundary lubrication film.

Keyword: Rice husk, Ceramic, Additive, Tribo-chemistry

\section{Introduction}

As a renewable biomass resource, rice husk $(\mathrm{RH})$, which is often burned in farms, releases pollutants that adversely affect the environment. Therefore, the comprehensive utilization of RH is particularly important. RH can be utilized to prepare biomass fuel [1], solid molding fuel [2], as a 


\section{ACCEPTED MANUSCRIPT}

biosorbent [3], and as functional materials $[4,5]$. The preparation of rice husk ceramic (RHC) particle is an appropriate technology for the comprehensive utilization of RH. RHC can be used as sliding elements in linear guiders and slides because of their special physical characters, such as high hardness, low Young's modulus, low friction coefficient, and high abrasion resistance.

At present, investigations on the tribological behaviors of RHC and rice bran ceramic (RBC) particles have been extensively reported. Dugarjav $\boldsymbol{e t} \boldsymbol{a l}$. [6] investigated the dry tribological behaviors of disk-shaped RHC with different friction pairs, such as high carbon-chromium steel, austenitic stainless steel, and $\mathrm{Al}_{2} \mathrm{O}_{3}$, under dry conditions using a ball-on-disk tribometer. The antiwear and friction reduction properties of RHC particles were ascribed to film formation on the steel balls. The same authors also investigated the effect of the variation of carbonization temperature $\left(900,1,400\right.$, and $\left.1,500{ }^{\circ} \mathrm{C}\right)$ on the tribological performance of RHC particles. They found that $900{ }^{\circ} \mathrm{C}$ was the optimum carbonization temperature [7]. Shibata et al. [8] also investigated the tribological performance of disk-shaped RHC materials sliding against stainless steel, alumina, silicon carbide, and silicon nitride under dry conditions. They determined that RHC particles exhibited the best tribological performance when sliding against silicon nitride balls, which was again be ascribed to the formation of a transfer film on the $\mathrm{Si}_{3} \mathrm{~N}_{4}$ balls. Moreover, they also assessed the tribological behavior of the disk-shaped copper/carbon/RBC $(\mathrm{Cu} / \mathrm{C} / \mathrm{RBC})$ composite materials, which evidently promoted antiwear and friction reduction properties in composite materials under water-lubricated conditions [9]. The microscopic wear mechanism of the $\mathrm{Cu} / \mathrm{C} / \mathrm{RBC}$ composite included the appearance of different wear modes under low or high wear conditions, and was verified, with a corresponding wear map [9-11]. Akiyama et al. [12, 13] developed five thermoplastic resin/RBC composite materials, and their tribological performances 
were assessed using a linear reciprocating tribometer under dry and oil lubricated conditions. They determined that the friction coefficient and antiwear properties of composite materials were evidently lower than those of neat thermoplastic resins. From these results, it can be concluded that RHC or RBC particles have and comtinue to be extensively applied as acomposite fillers in variety of materials .

In view of the superior tribological performance of RHC and RBC particles, it seems reasonable therefore to test RHC particles as an additive in lubricating oils. At present, research on the use of RHC particles as an lubricant additive, particularly on the effect of RHC on the tribological behavior of liquid paraffin (LP) remains limited. In the present study, a series of system tribological tests have been conducted to investigate the effect of RHC particles as an additive on the lubrication properties of LP containing $2 \mathrm{wt} \%$ polyisobutylene succinimide (T154A) to extend the application of RHC particles.

\section{Experimental}

\subsection{Materials and samples preparation}

The RHC particles were prepared using the carbonization process with a mass rate of 3:1 for RH powder (mesh size 10, purchased from Yuanyang Yanbing Rice Industry Co. Ltd. China) and phenolic resin (PR, Model 3122, purchased from Wuxi Mingyang Adhesive Material Co. Ltd. China). Exactly $2.5 \mathrm{~g}$ of PR was added to $7.5 \mathrm{~g}$ RH power, and the mixture was stirred using a glass rod for $15 \mathrm{~min} .3 \mathrm{~g}$ the mixture was transferred to a porcelain crubile and placed in a tube furnace (Model OTF-1200X) at $900{ }^{\circ} \mathrm{C}$ and under $\mathrm{N}_{2}$ atmosphere conditions for $2 \mathrm{~h}$ and then 


\section{ACCEPTED MANUSCRIPT}

removed and allowed to cooled to room temperature. The remaining power was RHC particles

[14]. The productivity of RHC particles was approximate $31 \%$.

A commercially available LP was purchased from Tianjin Fuyu Chemical Co. Ltd. in China. . A dispersant, Poly-isobutylene succinimide (T154A supplied by the Shang hai Demao Chemical Co., Ltd.) was utilized to ensure the uniform dispersion of the RHC particles in the LP, in a method described by [15]. The oil samples were LP $+2 \mathrm{wt} \% \mathrm{~T} 154 \mathrm{~A}, \mathrm{LP}+2 \mathrm{wt} \% \mathrm{~T} 154 \mathrm{~A}+0.01$ $w t \%$ RHC, LP + $2 w t \%$ T154A + $0.03 w t \%$ RHC, and LP + $2 w t \% ~ T 154 A+0.05 w t \%$ RHC. The tests sampels were prepared by magnetic stirring for $2 \mathrm{~h}$ to reduce experimental deviation. The other reagents, such as ethanol and acetone, were all analytical grade.

\subsection{Analysis methods}

The internal structure and primary particle of RHC were analyzed using a high-resolution transmission electron microscope (HRTEM, JEOL-2010) at an acceleration voltage of $200 \mathrm{kV}$. For the investigation, a drop of ethanol solution, including RHC particles, was placed onto the HRTEM Cu grids that were supported by thin carbon films. Then, scanning electron microscopy coupled with energy dispersive spectroscopy (SEM/EDS, model JSM-6700F) was used to investigate the agglomeration morphology of the RHC particles.

Figure 1 shows the agglomerated morphology, internal structure, and primary particle of the RHC particles. The SEM image shown in Figure 1(a) reveals that the morphology of RHC particles was sheet-shaped, which was consistent with that shown in Figure 1(b). A large amount of amorphous carbon exists in a single RHC particle, as shown in Figure 1(c) and proven by Raman analysis shown in Figure 1(d). The degree of graphitization disorder $\left(I_{D} / I_{G}\right)$ of RHC was 


\section{ACCEPTED MANUSCRIPT}

$3.64[14,16]$. In general, the D peak $\left(1350 \mathrm{~cm}^{-1}\right)$ could be attributed to the disordered graphite lattices, and the $\mathrm{G}$ peak $\left(1580 \mathrm{~cm}^{-1}\right)$ to the ideal graphitic lattices. The higher intensity of the $\mathrm{G}$ peak, the higher graphitization degree [16].

The tribological tests were conducted on a four-ball tribometer (Model MRS-10D) at $200 \mathrm{~N}$ and $1,450 \mathrm{rpm}$ and under three temperature levels $\left(25,75\right.$, and $\left.100{ }^{\circ} \mathrm{C}\right)$ for $30 \mathrm{~min}$. The steel balls used in the tests were ASTM E2100 grade bearing steel with a diameter of $12.7 \mathrm{~mm}$, fabricated according to the national Chinese standard GB/T308-2002. The hardness of the steel specimens was $\mathrm{HRC}=65$ with an average surface roughness of $\mathrm{Ra}=0.012 \mu \mathrm{m}$. Under the experimental parameters selected, the maximum Hertzian contact pressure at the start of the tests was $3.93 \mathrm{GPa}$. With these conditions, the lubrication regime will fall under boundary lubrication condition[17]. All oil samples were processed with ultrasonic dispersion treatment for $20 \mathrm{~min}$ to reduce the experimental deviation. The morphologies of the wear zones and the element composition on the surfaces were analyzed via SEM/EDS and 3D laser scanning microscopy (Model VK-X100k). The chemical element valences were investigated by X-ray photoelectron spectroscopy (Model ESCALAB 250). The structure of carbon on the wear zones was also investigated by Raman spectroscopy with the laser at $532 \mathrm{~cm}^{-1}$ and Stokes Raman shift of $100-3,500 \mathrm{~cm}^{-1}$ [18].

\section{Results and discussion}

\subsection{Friction reduction}

Figure 2 shows the variations of the friction coefficients of materials lubricated with LP, including different contents of RHC particles, with $2 \mathrm{wt} \% \mathrm{~T} 154 \mathrm{~A}$ at 25,75 , and $100{ }^{\circ} \mathrm{C}$. There was very little change in the friction coefficients of materials lubricated with the different RHC 


\section{ACCEPTED MANUSCRIPT}

impregnated at $25^{\circ} \mathrm{C}$, as shown in Figure 2(a).

Figures 2(b) and 2(c) show the variations of the friction coefficients of the materials lubricated with oil samples at 75 and $100{ }^{\circ} \mathrm{C}$. Notably, the friction coefficients of materials lubricated with LP containing $2 \mathrm{wt} \%$ T154A, increased significantly compared with that of pure LP. However, the friction coefficients all decreased when different contents of RHC in LP were added, indicating that at elevated temperatures enhances the lubrication property of oil samples were enhanced. This phenomenon can also be observed when the material is lubricated with oil samples at $100^{\circ} \mathrm{C}$, as shown in Figure 3(c).

\subsection{Wear resistance}

Figure 3(a) shows the variations of average wear scar diameter (AWSDs) lubricated with oil samples at different temperatures. The variation of the AWSDs of the steel balls was not obvious when the T154A or the RHC particles were added into the liquid paraffin at $25{ }^{\circ} \mathrm{C}$. The AWSD of pure LP was $0.55 \mathrm{~mm}$ at $25^{\circ} \mathrm{C}$. The AWSDs all decreased slightly when different contents of RHC particles were added to LP containing 2 wt $\%$ T154A. However, as oil temperatures were elevated to $75^{\circ} \mathrm{C}$, there was an obvious reduction in the AWSD when $2 \mathrm{wt} \%$ T154A was added. The AWSD

of pure LP was $0.60 \mathrm{~mm}$ at $75^{\circ} \mathrm{C}$. When the RHC particles were added to the LP, the AWSDs of the oil samples evidently decreased. The AWSDs decreased to 0.38 and 0.36 when 0.01 and 0.03 wt\% RHC particles were added, respectively. These results prove that the RHC particles improve the wear resistance of LP. Interestingly, when $0.05 \mathrm{wt} \%$ RHC particles was added wear suddenly increased, which was possibly attributed to the decrease of the dispersant efficacy and the subsequent agglomeration of RHC particles. The AWSDs were all approximately $0.39 \mathrm{~mm}$ at $100{ }^{\circ} \mathrm{C}$. The AWSDs did not vary evidently when the RHC particles were added to LP. The AWSD 


\section{ACCEPTED MANUSCRIPT}

of LP containing $0.05 \mathrm{wt} \%$ RHC decreased to slightly to $0.37 \mathrm{~mm}$. These phenomena reflected that the RHC particles did not improve the antiwear property of LP significantly at the higher temperature. However, the wear resistance properties of the same oil samples showed a same improment with the increase in temperature from $25{ }^{\circ} \mathrm{C}$ to $100{ }^{\circ} \mathrm{C}$ for the same test conditions. For example, the AWSD was $0.50 \mathrm{~mm}$ at $25{ }^{\circ} \mathrm{C}$ for $\mathrm{LP}$ containing $0.03 \mathrm{wt} \% \mathrm{RHC}$. When the temperature increased, the AWSDs were $0.38 \mathrm{~mm}\left(75^{\circ} \mathrm{C}\right)$ and $0.37 \mathrm{~mm}\left(100{ }^{\circ} \mathrm{C}\right)$. The results indicated that the tribo-film played an important role in wear resistance resulting in a variation of AWSDs when the dispersant and particles were added at $100^{\circ} \mathrm{C}$.

\subsection{Surface analysis}

Figure 4 shows the morphologies of the wear zones of the rotational and stationary steel specimens lubricated with pure LP and LP with $0.03 \mathrm{wt} \%$ RHC particles and $2 \mathrm{wt} \%$ T154A. Many pits and furrows appeared on the surface of the rotational steel ball lubricated with pure LP at $25^{\circ} \mathrm{C}$, denoted by the red rectangle. The corresponding surface roughness was $0.50 \mu \mathrm{m}$. A smooth surface was obtained when the temperature increased to $100{ }^{\circ} \mathrm{C}$, and the pits and furrows almost disappeared. Moreover, the AWSD was evidently decreased compared with that of LP at $25^{\circ} \mathrm{C}$. The surface roughness of the rotational ball decreased to $0.34 \mu \mathrm{m}$ by some $32 \%$. Furrows were also evidently observed on the surface of the rotational ball when only 2 wt $\%$ the T154A dispersant was added to the $\mathrm{LP}$ at $25^{\circ} \mathrm{C}$. The surface roughness was $0.48 \mu \mathrm{m}$. At $100{ }^{\circ} \mathrm{C}$, the furrows became indistinct and AWSD decreased compared with that of $25{ }^{\circ} \mathrm{C}$. The surface roughness of the rotational ball showed a $27 \%$ decrease to $0.35 \mu \mathrm{m}$. Adding $2 \mathrm{wt} \%$ T154A and $0.03 \mathrm{wt} \% \mathrm{RHC}$ to $\mathrm{LP}$ at $25{ }^{\circ} \mathrm{C}$, furrows were observed, as well as evidence of a tribo-film, as shown in the high-magnification SEM images, and the corresponding zone marked by the red 


\section{ACCEPTED MANUSCRIPT}

rectangle. The surface roughness was $0.45 \mu \mathrm{m}$. The morphology of the stationary steel ball also provides evidence (denoted by the blue rectangle in Figure 4) of the formation of the tribofilm within the wear zone lubricated with LP containing $0.03 \mathrm{wt} \%$ RHC particles and $2 \mathrm{wt} \%$ T154A. At $100{ }^{\circ} \mathrm{C}$, the furrows were uniformly distributed. Notably, the surface roughness decreased to 0.27 by $33.4 \%$ compared with that at $25{ }^{\circ} \mathrm{C}$, which indicated that the RHC particles enhance the wear resistance property of LP containing $2 \mathrm{wt} \% \mathrm{~T} 154 \mathrm{~A}$ at $100{ }^{\circ} \mathrm{C}$.

Figure 5 shows the kinds and elemental composition of the worn traces lubricated with different oil samples at 25 and $100{ }^{\circ} \mathrm{C}$. The elements $\mathrm{C}, \mathrm{O}, \mathrm{Fe}$, and $\mathrm{Cr}$ were detected on the worn trace lubricated with $\mathrm{LP}$ at $25^{\circ} \mathrm{C}$, and the element $\mathrm{Al}$ was discounted as it was ascribed to the aluminum-based sample table to fix the rotational steel ball. The elements $\mathrm{C}, \mathrm{O}, \mathrm{Fe}$, and $\mathrm{Cr}$ were also detected on the worn trace lubricated with pure LP at $100^{\circ} \mathrm{C}$. Notably, the $\mathrm{O}$ content of the worn trace lubricated with $\mathrm{LP}$ at $100{ }^{\circ} \mathrm{C}$ was lower that at $25{ }^{\circ} \mathrm{C}$. The variation of the type and contents of the elements was relatively small when $2 \mathrm{wt} \%$ T154A was added to LP. The Si content was checked when adding the RHC particles to LP containing 2 wt\% T154A. The inset SEM image proves that the RHC particle is involved in the formation of the tribofilm, denoted by the red rectangle. The $\mathrm{C}$ content was also evidently increased compared with those of pure LP or LP containing $2 \mathrm{wt} \% \mathrm{~T} 154 \mathrm{~A}$, providing sufficient evidence of the involvement of RHC particles in the formation of the tribofilm. When the test temperature was increased to $100{ }^{\circ} \mathrm{C}, \mathrm{Si}$ was also observed. These phenomena can be used for preliminary verification of the variations of the friction coefficients, and AWSDs decreased at $100^{\circ} \mathrm{C}$.

\subsection{Friction mechanisms analysis}

RHC particles have $\mathrm{Si}, \mathrm{C}$, and $\mathrm{O}$ elements, and the average particle size was approximately 


\section{ACCEPTED MANUSCRIPT}

$78 \mu \mathrm{m}$ [14]. Sheet-shaped particle will have been critical to the formation of a boundary lubrication film. The elemental chemical valences of worn traces lubricated with different oil samples were investigated, as shown in Figures 6, 7, 8, and 9. The peak at $284.5 \mathrm{eV}$ was attributed to $\mathrm{C}-\mathrm{C}$ or $\mathrm{C}-\mathrm{H}$. Figure 6 shows the carbon chemical valence of worn traces lubricated with different oil samples at 25 and $100{ }^{\circ} \mathrm{C}$. Only one peak was detected at $284.5 \mathrm{eV}$, which can be attributed to $\mathrm{C}-\mathrm{C}$ or $\mathrm{C}-\mathrm{H}$. Figure 7 shows the variations of the oxygen element chemical valence of worn traces lubricated with different oil samples at 25 and $100{ }^{\circ} \mathrm{C}$. In general, the peak at 529 $530 \mathrm{eV}$ was attributed to metal oxides and the peak at $531.4 \mathrm{eV}$ was attributed to hydroxides (including - $-\mathrm{OH}$ ). Moreover, the peaks at 532.4 and $103.2 \mathrm{eV}$ can be attributed to silicones, as shown in Figure 9(b), indicating that the boundary lubrication film also contained silicones. Figure 8 shows the variations of the iron element chemical valences on the worn traces. The peak at 709-711.5 eV can be attributed to $\mathrm{FeO}, \mathrm{Fe}_{2} \mathrm{O}_{3}$, or $\mathrm{Fe}_{3} \mathrm{O}_{4}$. $\mathrm{FeO}, \mathrm{Fe}_{2} \mathrm{O}_{3}$, and $\mathrm{Fe}_{3} \mathrm{O}_{4}$ possibly formed on the worn traces, as shown in Figures 8(a) and 8(b). However, the peak of Fe was relatively weak, so it was difficult to fully to determine whether iron oxides were presented on the worn surface of worn traces lubricated with LP containing 0.03 wt $\%$ RHC at $100{ }^{\circ} \mathrm{C}$. This phenomenon can be ascribed to low levels of elemental iron resulting from the friction-induced formation of a boundary lubrication film containing RHC particles, such that the peak became weak. Figure 9 provides further evidence that the RHC particles were involved in the formation of the lubrication film. The peak at $103.2 \mathrm{eV}$ can be attributed to silicones, derived from the RHC particles added to LP [19-21].

Raman spectroscopy was conducted to verify the formation of the boundary lubrication film on the worn traces, and the results are shown in Figure 10. Generally, the range of the peak 
between 214-670 $\mathrm{cm}^{-1}$ for $\mathrm{Fe}$ can be ascribed to iron oxides, such as $\mathrm{FeO}, \mathrm{Fe}_{2} \mathrm{O}_{3}$, or $\mathrm{Fe}_{3} \mathrm{O}_{4}$ [22]. These peaks were all detected when RHC was added to LP containing 2 wt\% T154A at both 25 and $100{ }^{\circ} \mathrm{C}$. Moreover, the D and G peaks of carbon that can be attributed to the RHC particles were all detected, indicating that the RHC particles were involved in the formation of the boundary lubrication film [23].

The boundary lubrication film composed of RHC particles was assessed to verify the variations of the friction coefficients and AWSDs of worn traces lubricated with different oil samples at 25,75 , and $100{ }^{\circ} \mathrm{C}$. The formation of a local tribofilm including RHC particles at $25^{\circ} \mathrm{C}$, as shown in magnified SEM image in Figure 5, resulted in a small decrease of friction coefficient. A similar film was detected at the high temperatures $\left(75\right.$ or $\left.100{ }^{\circ} \mathrm{C}\right)$, moreover, but under these conditions the RHC particles restore the integrity of the surface within the worn zone, resulting in a lower surface roughness and friction coefficient [17]. In summary, high oil temperatures (75 and $100{ }^{\circ} \mathrm{C}$ ) catalyze improved wear resistance and friction reduction properties of LP containing $2 \mathrm{wt} \%$ T154A and different contents of RHC particles compared with that of pure LP at $25^{\circ} \mathrm{C}$.

\section{Conclusions}

In this study, the effect of RHC particles on the lubrication performance of LP containing 2 wt $\%$ T154A was investigated using a four-ball tribometer at 25,75 , and $100{ }^{\circ} \mathrm{C}$. A series of system tribological tests was conducted to determine the friction and wear mechanisms of RHC particles. The following conclusions have been drawn:

1) The wear resistance and friction reduction properties of LP can be evidently modified when $0.01,0.03$, and $0.05 \mathrm{wt} \%$ RHC particles were added at a test temperature of 75 or $100{ }^{\circ} \mathrm{C}$. 


\section{ACCEPTED MANUSCRIPT}

2) The T154A and RHC particles act synergistically by enhancing the antiwear property of LP when $0.03 \%$ RHC particle and 2 wt $\%$ T154A were added. The AWSD decreased from 0.60 $\mathrm{mm}$ to $0.37 \mathrm{~mm}$ by $60 \%$.

3) The friction and wear mechanisms of RHC particles at 75 or $100{ }^{\circ} \mathrm{C}$ were ascribed to the formation of boundary lubrication film containing both carbon and silicones.

These results indicate that the RHC particles can become a potential functional additive in lubricating oils.

\section{Acknowledgements}

The authors wish to express their thanks to Mr. Yong Xu, Dr. Tianxia Liu for their assistance in the Raman spectroscopy and HRTEM tests. The financial support from the National Natural Science Foundation of China (Grant No. 51505121) and Anhui Provincial Natural Science Foundation (Grant No.1608085QE119, No. 1508085J10) and Anhui Provincial Students' Innovation and Entrepreneurship Training Program (Grant No: 201511059157) are gratefully acknowledged.

\section{References}

[1] Ikura M, Stanciulescu M, Hogan E.d. Emulsification of pyrolysis derived bio-oil in diesel fuel. Biomass and Bioenergy. 2003;24:221-32.

[2] Li P, Kanda H, Makino H. Simultaneous production of bio-solid fuel and bio-crude from vegetal biomass using liquefied dimethyl ether. Fuel. 2014;116:370-6.

[3] Chuah TG, Jumasiah A, Azni I, Katayon S, Thomas Choong SY. Rice husk as a potentially low-cost biosorbent for heavy metal and dye removal: an overview. Desalination. 2005;175:305-16. 


\section{ACCEPTED MANUSCRIPT}

[4] Soltani N, Bahrami A, Pech-Canul MI, González LA. Review on the physicochemical treatments of rice husk for production of advanced materials. Chemical Engineering Journal. 2015;264:899-935.

[5] Jenkins BM. Global Agriculture: Industrial feedstocks for energy and materials. In: Alfen NKV, editor. Encyclopedia of Agriculture and Food Systems. Oxford: Academic Press; 2014., p. 461-98.

[6] Dugarjav T, Yamaguchi T, Shibata K, Hokkirigawa K. Friction and wear properties of rice husk ceramics under dry condition. Journal of Mechanical Science and Technology. 2010;24:85-8.

[7] Dugarjav T, Yamaguchi T, Katakura S, Hokkirigawa K. The effect of carbonizing temperature on friction and wear properties of hard porous carbon materials made from rice husk. Tribology Online. 2009;4:11-6.

[8] Shibata K, Yamaguchi T, Hokkirigawa K. Tribological behavior of RH ceramics made from rice husk sliding against stainless steel, alumina, silicon carbide, and silicon nitride. Tribology International. 2014;73:187-94.

[9] Shibata K, Yamaguchi T, Hokirrigawa K. Wear and friction properties of Copper/Carbon/Rich Bran ceramics composite under water lubricated-condition. Tribology Online. 2010;6:180-4

[10] Shibata K, Yamaguchi T, Urabe T, Hokkirigawa K. Experimental study on microscopic wear mechanism of copper/carbon/rice bran ceramics composites. Wear. 2012;294-295:270-6.

[11] Shibata K, Yamaguchi T, Yao Y, Yokoyama N, Mishima J, Hokkirigawa K. Friction and wear properties of Copper/Carbon/RB ceramics composite under electrical current. Tribology 


\section{ACCEPTED MANUSCRIPT}

online. 2009;4:131-4.

[12] Akiyama M, Yamaguchi T, Matsumoto K, Hokkirigawa K. Polymer composites filled with RB ceramics particles as low friction and high wear resistant filler. Tribology online. 2010;5:19-26.

[13] Akiyama M, Yamaguchi T, Matsumoto K, Hokkirigawa K. Friction and wear of polyamide 66 composites filled with RB ceramics particles under dry condition. Tribology Online. 2010;5:87-91.

[14] Hu E, Hu K, Xu Z, Hu X, Dearn KD, Xu Y, et al. Investigation into the morphology, composition, structure and dry tribological behavior of rice husk ceramic particles. Applied Surface Science. 2016;366C:372-82.

[15] Hu E, Hu X, Liu T, Song R, Dearn KD, Xu H. Role of $\mathrm{TiF}_{3}$ catalyst in the tribological properties of biofuel soot-contaminated liquid paraffin. Tribology International. 2014;77:122-31.

[16] Hu E, Hu X, Liu T, Liu Y, Song R, Chen Y. Investigation of morphology, structure and composition of biomass-oil soot particles. Applied Surface Science. 2013;270:596-603.

[17] Hu E, Hu X, Liu T, Fang L, Dearn KD, Xu H. The role of soot particles in the tribological behavior of engine lubricating oils. Wear. 2013;304:152-61.

[18] Shimodaira N, Masui A. Raman spectroscopic investigations of activated carbon materials. Journal of Applied Physics. 2002;92:902.

[19] http://www.lasurface.com/database/elementxps.php.

[20] Amirthan G, Balasubramanian M. Reciprocating sliding wear studies on $\mathrm{Si} / \mathrm{SiC}$ ceramic composites. Wear. 2011;271:1039-49.

[21] Matsuo Y, Tsuruda T, Kumagai S. Sliding properties of rice husk-derived Carbon/Silica 
composite. Journal of the Society of Materials Engineering for Resources of Japan. $2012 ; 24: 31-5$

[22] Shi J, Xin G, Wang X, Zhang Z. Raman spectroscopic studies of the rust process on a fresh iron surface. Journal of Shanghai Teachers University (Natural Sciences). 2001;30:62-6.

[23] Yamauchi S, Kurimoto Y. Raman spectroscopic study on pyrolyzed wood and bark of Japanese cedar: temperature dependence of Raman parameters. Journal of Wood Science. 2003;49:235-40.

\section{Highlights}

- The tribological behavior of RHC particles as a functional additive in LP was investigated at different temperature.

- The introduction of RHC particles into LP can obviously enhance lubrication property of LP containing $2 \mathrm{wt} \% \mathrm{~T} 154 \mathrm{~A}$ at 75 and $100{ }^{\circ} \mathrm{C}$.

- The friction and wear mechanisms of RHC particles were ascribed to high temperature, which ensures the involvement of RHC particles in the formation of boundary lubrication film. 


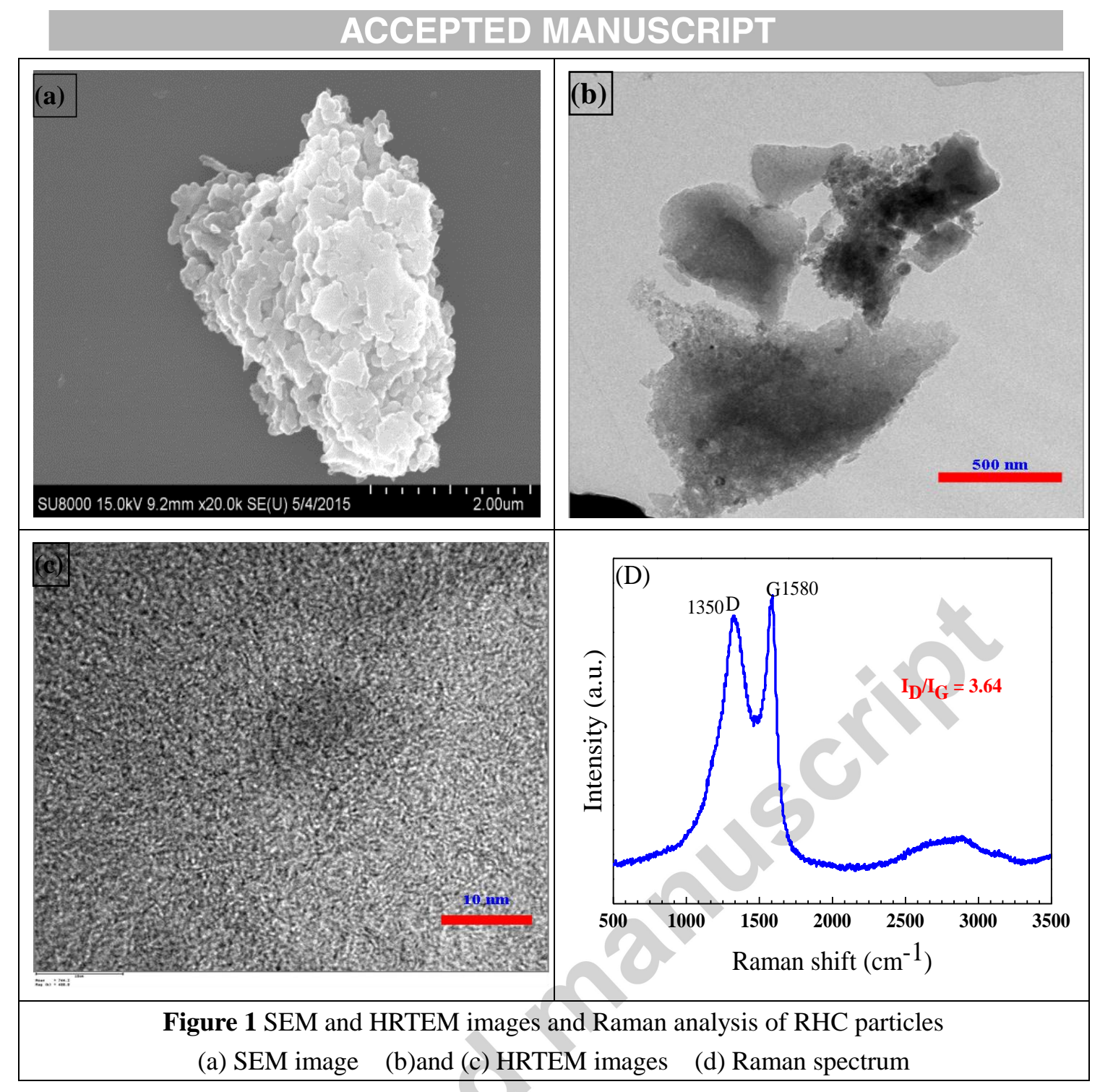



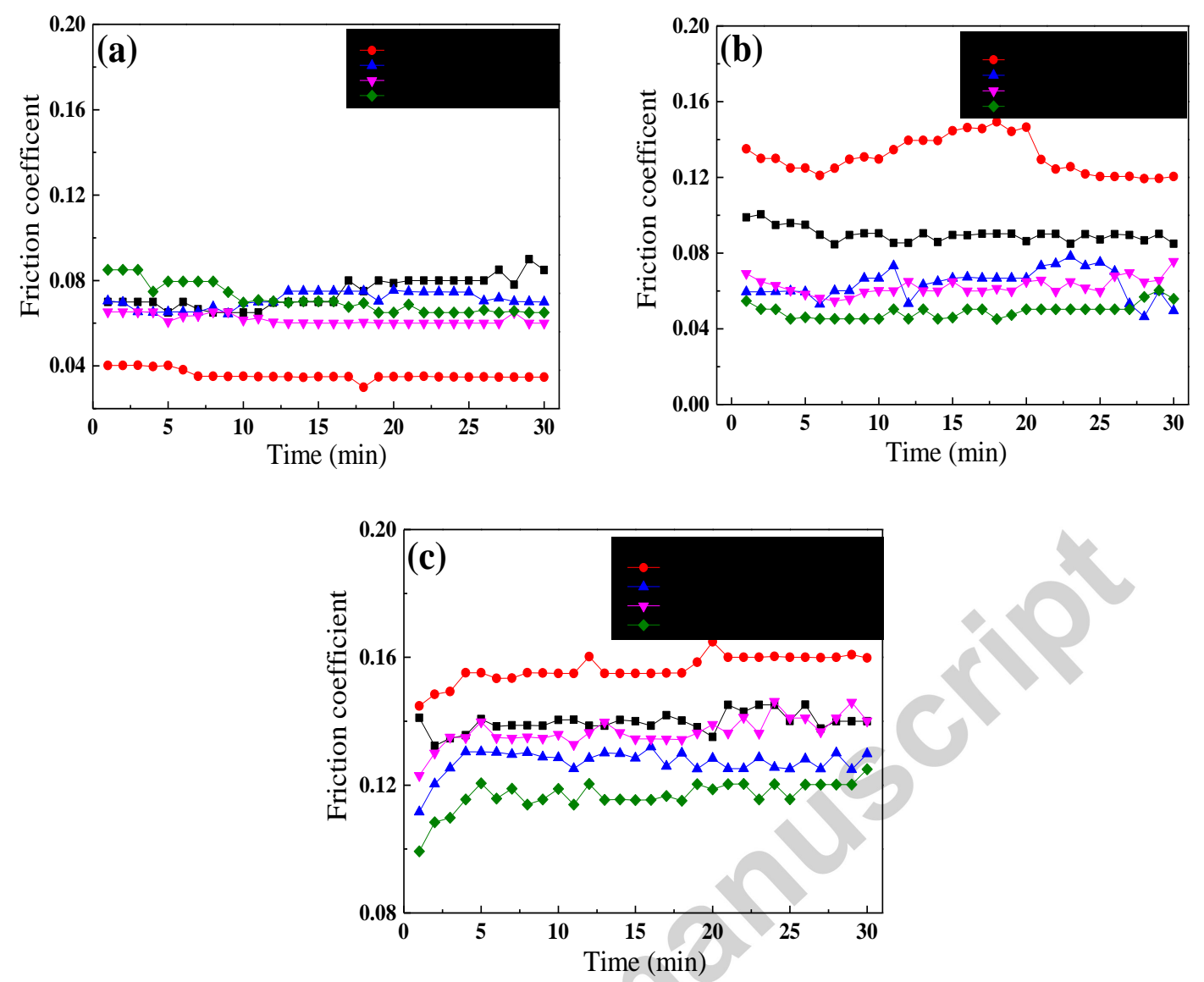

Figure 2 Variation of friction coefficient lubricated with the different contents of RHC particles in LP including $2 \mathrm{wt} \% \mathrm{~T} 154 \mathrm{~A}$ at $200 \mathrm{~N}$ and $1450 \mathrm{rpm}$ for $30 \mathrm{~min}$
(a) $25^{\circ} \mathrm{C}$;
(b) $75^{\circ} \mathrm{C}$;
(c) $100{ }^{\circ} \mathrm{C}$ 


\section{ACCEPTED MANUSCRIPT}
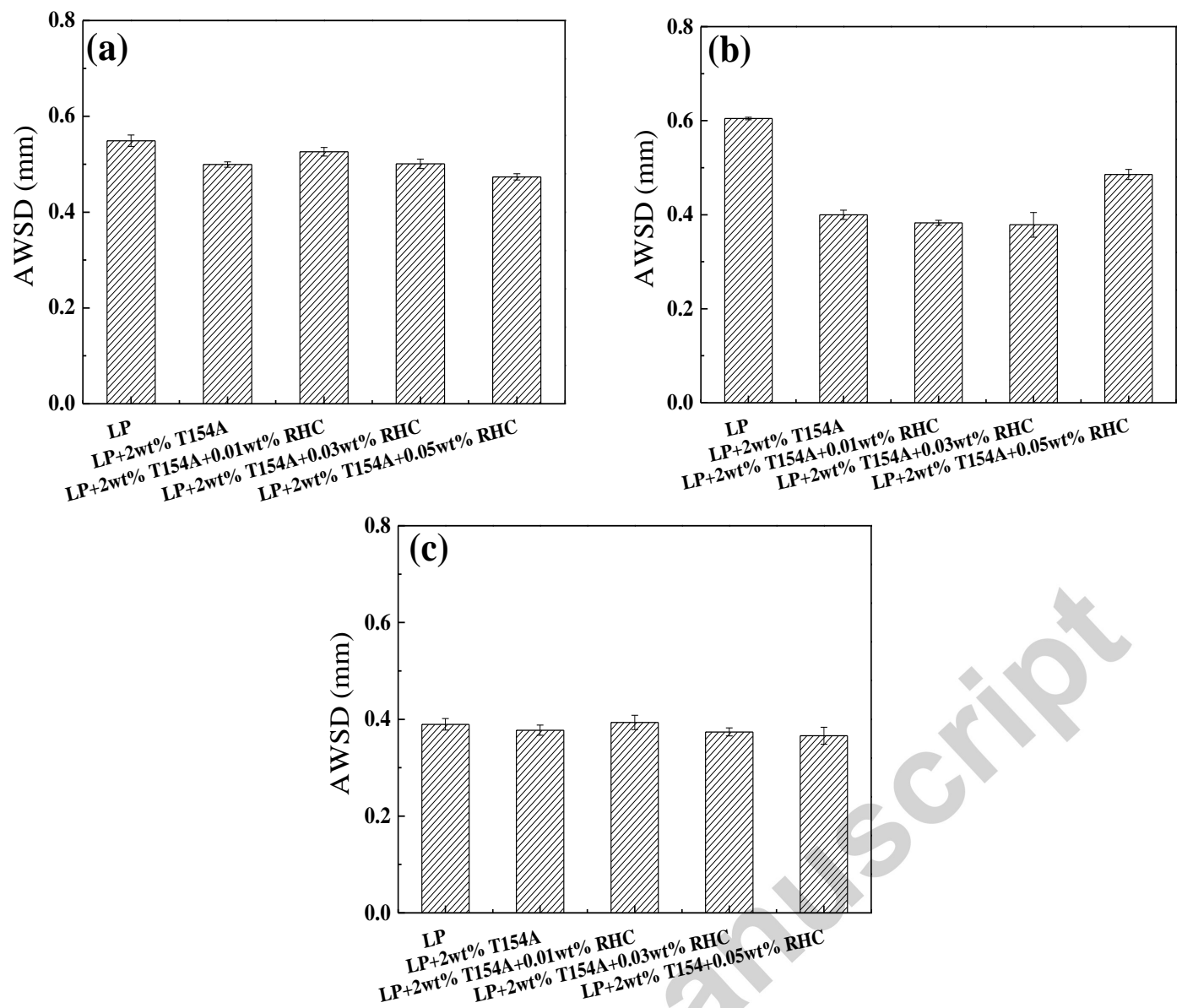

Figure 3 Variation of AWSDs lubricated with the different contents of RHC particles in LP including $2 \mathrm{wt} \% \mathrm{~T} 154$ at $200 \mathrm{~N}$ and $1450 \mathrm{rpm}$ for $30 \mathrm{~min}$
(a) $25{ }^{\circ} \mathrm{C}$;
(b) $75^{\circ} \mathrm{C}$;
(c) $100{ }^{\circ} \mathrm{C}$ 


\section{ACCEPTED MANUSCRIPT}

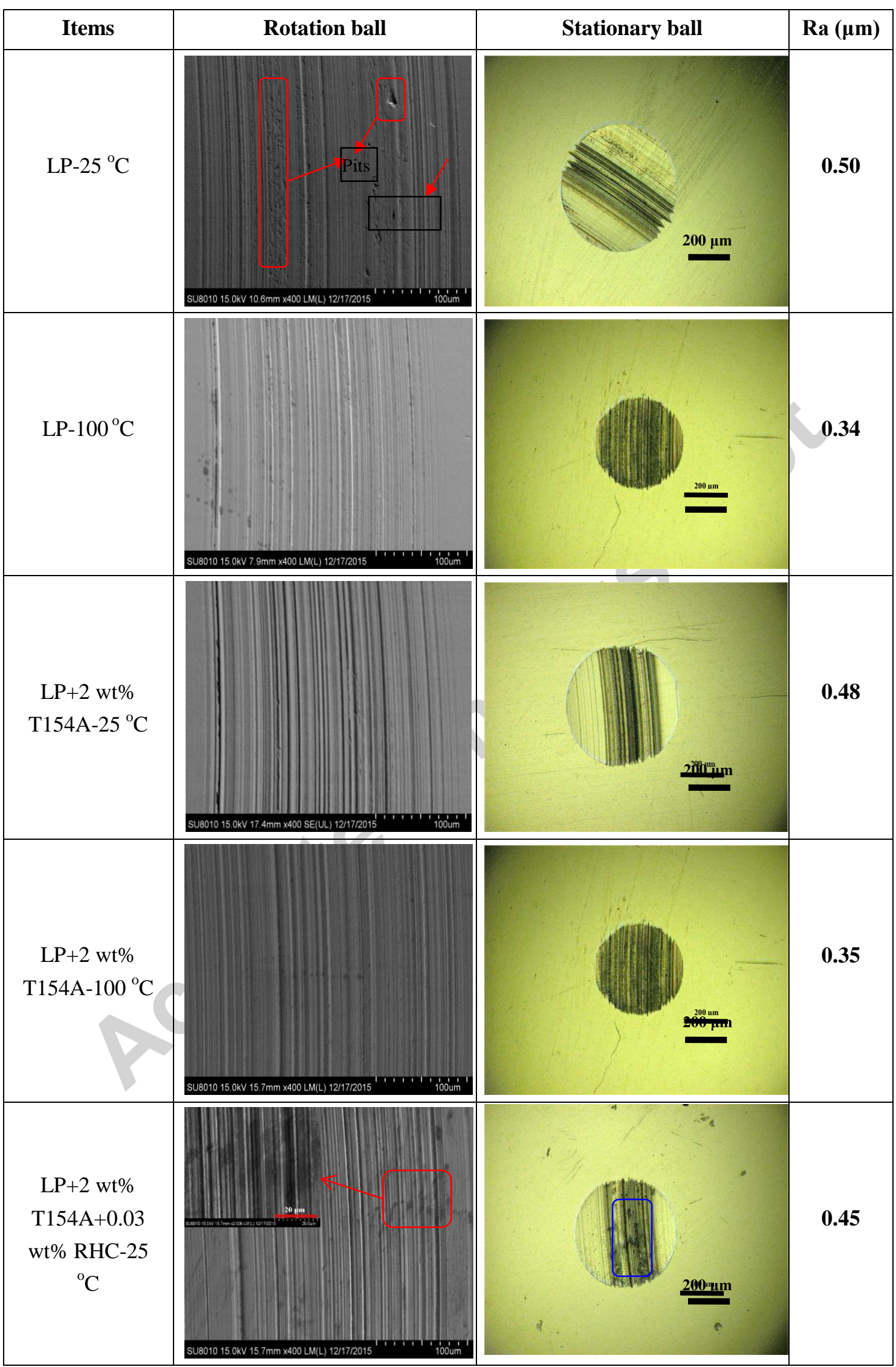




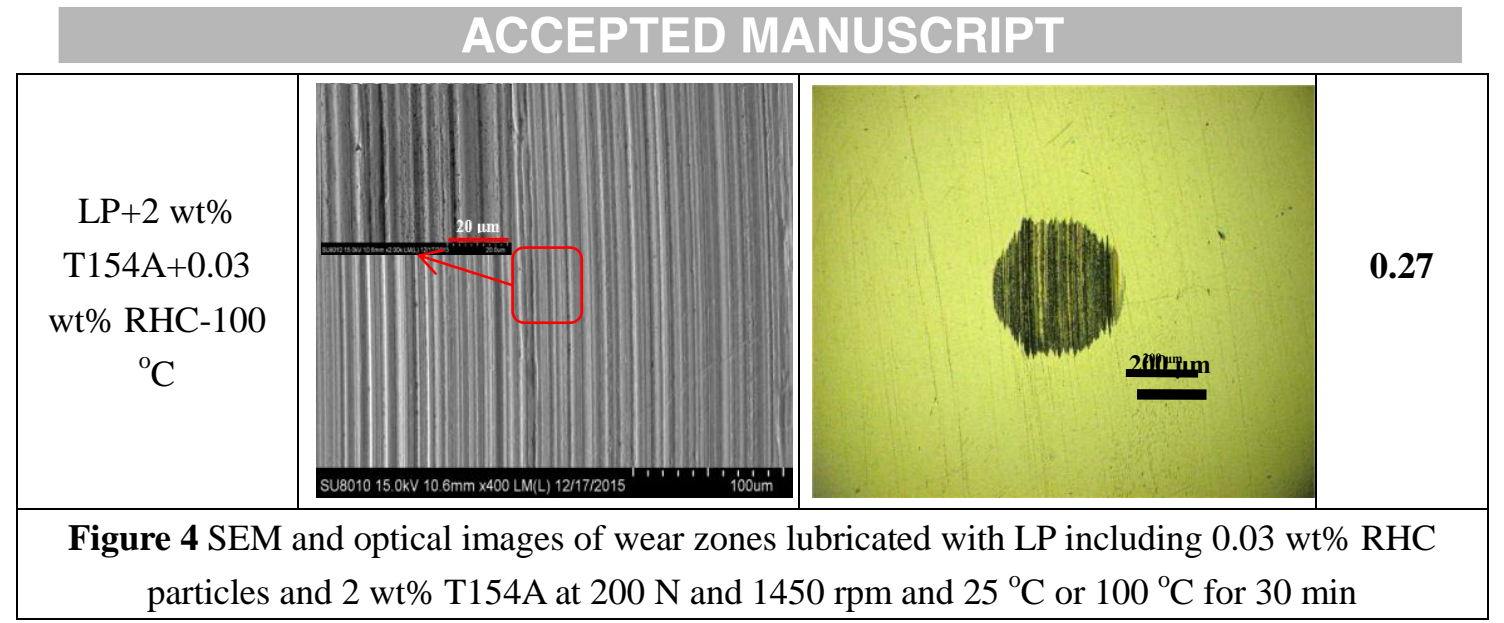




\section{ACCEPTED MANUSCRIPT}

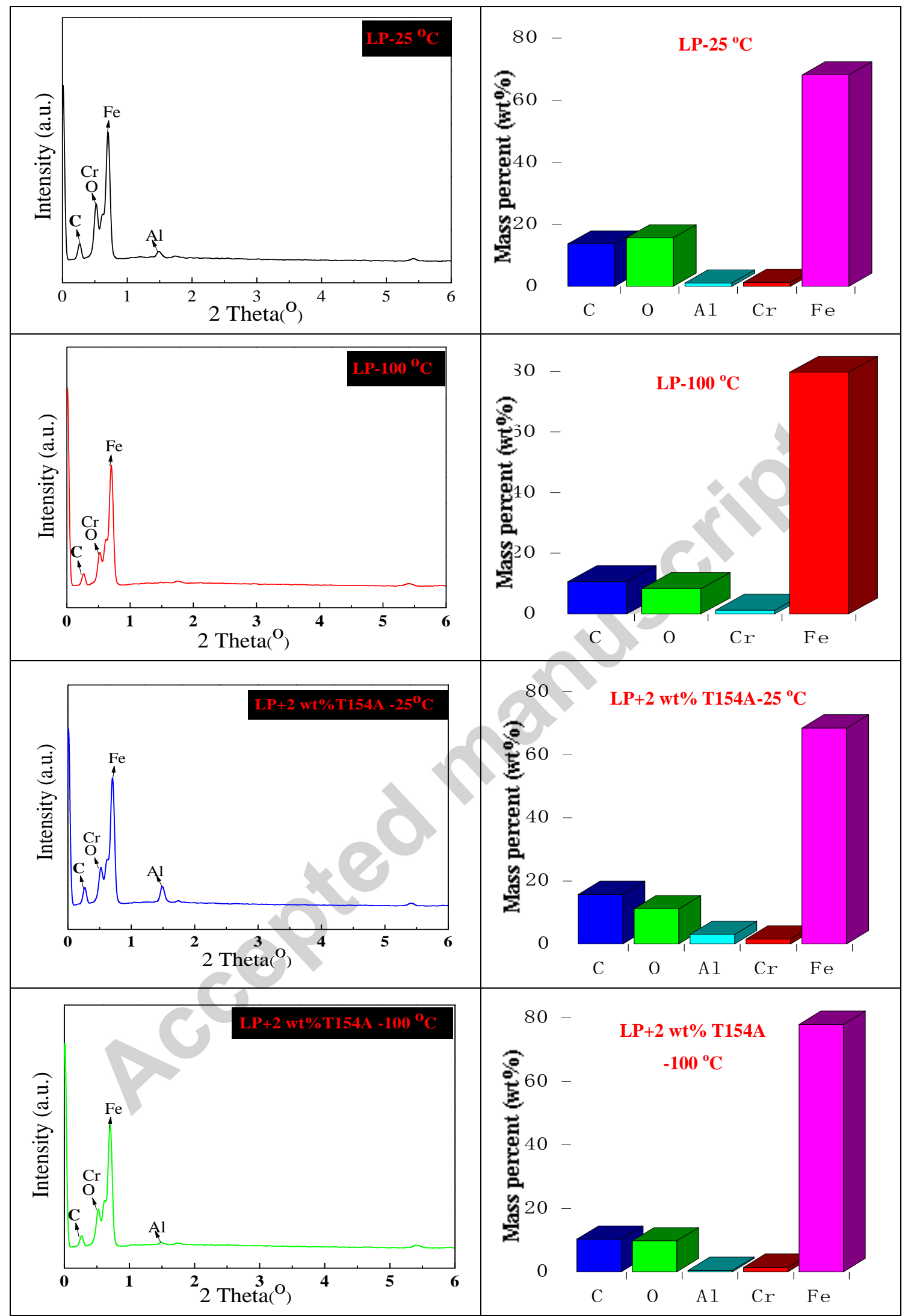




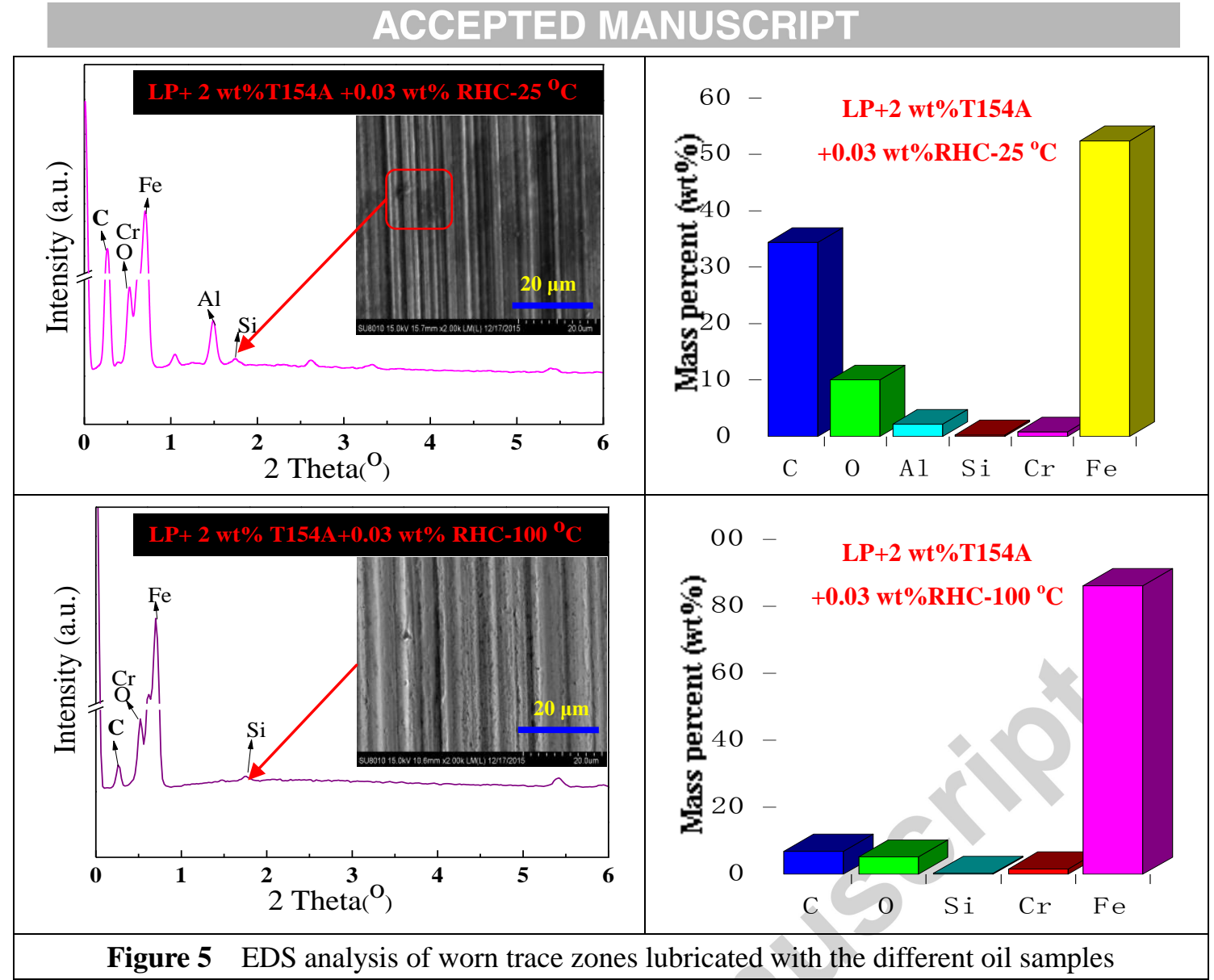



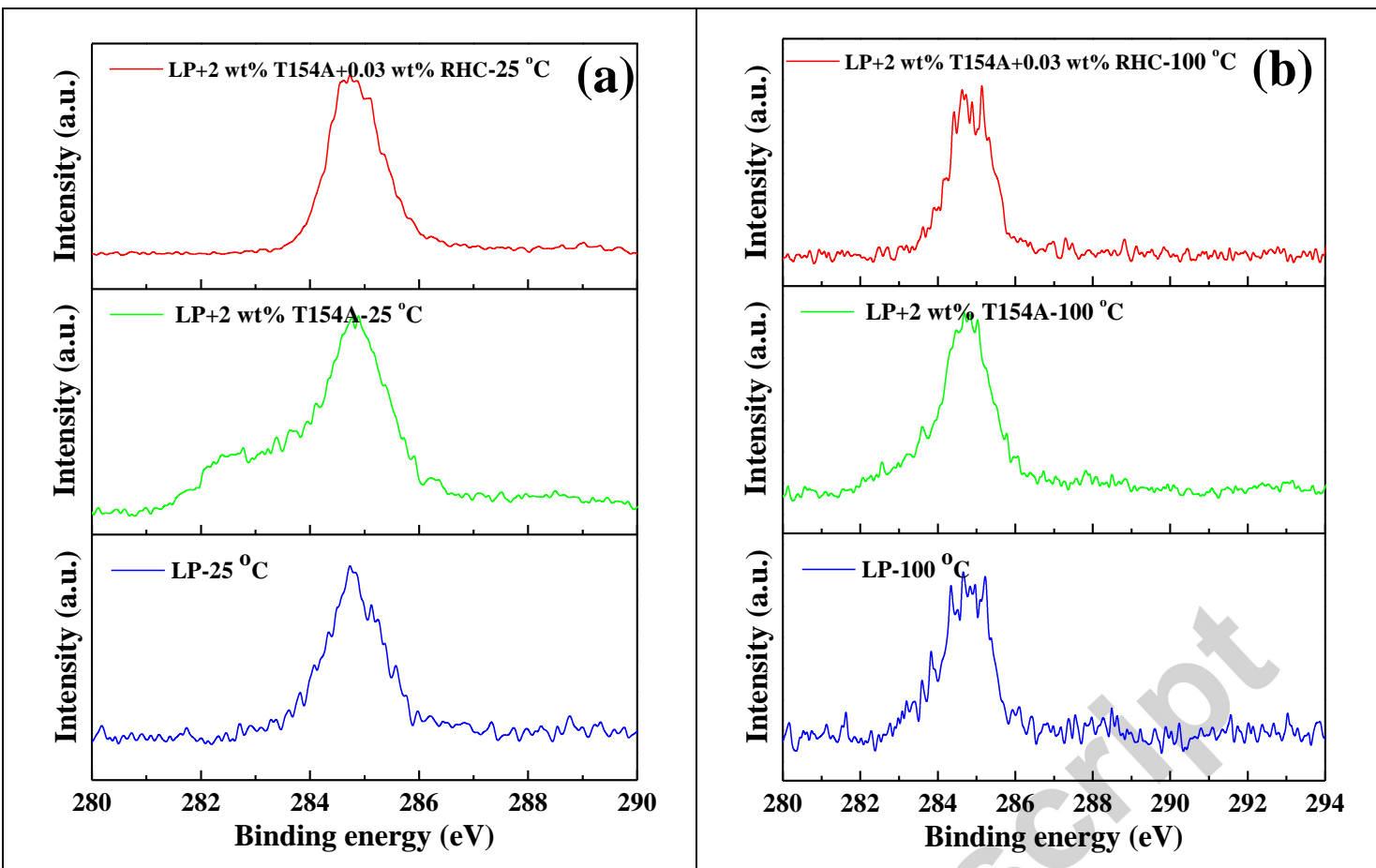

Figure 6 The $\mathrm{C}_{1 \mathrm{~s}}$ spectra of worn traces lubricated with different oil samples (a) $25^{\circ} \mathrm{C}$ (b) $100{ }^{\circ} \mathrm{C}$ 

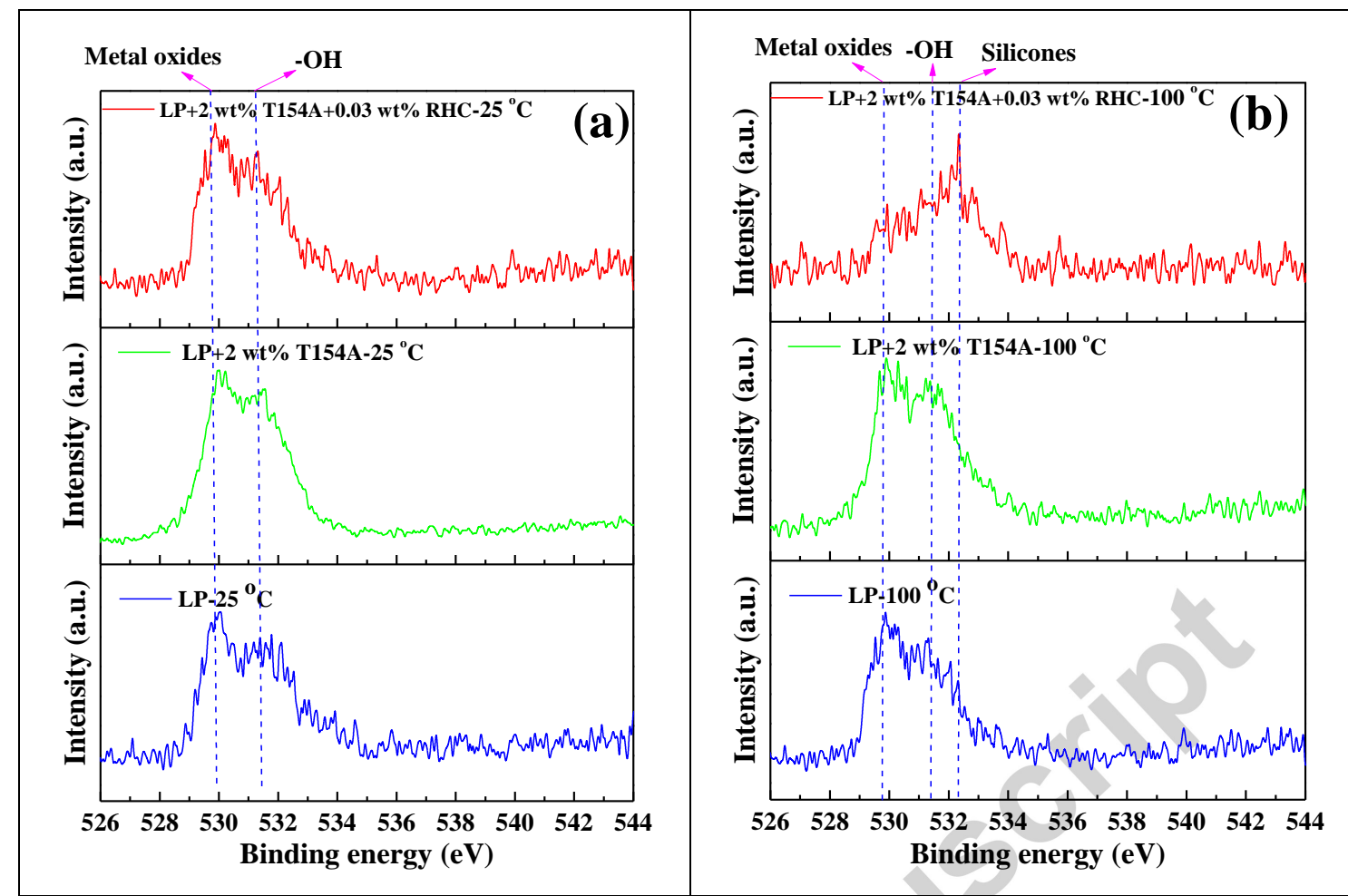

Figure 7 The $\mathrm{O}_{1 \mathrm{~s}}$ spectra of worn traces lubricated with different oil samples
(a) $25{ }^{\circ} \mathrm{C}$
(b) $100^{\circ} \mathrm{C}$ 

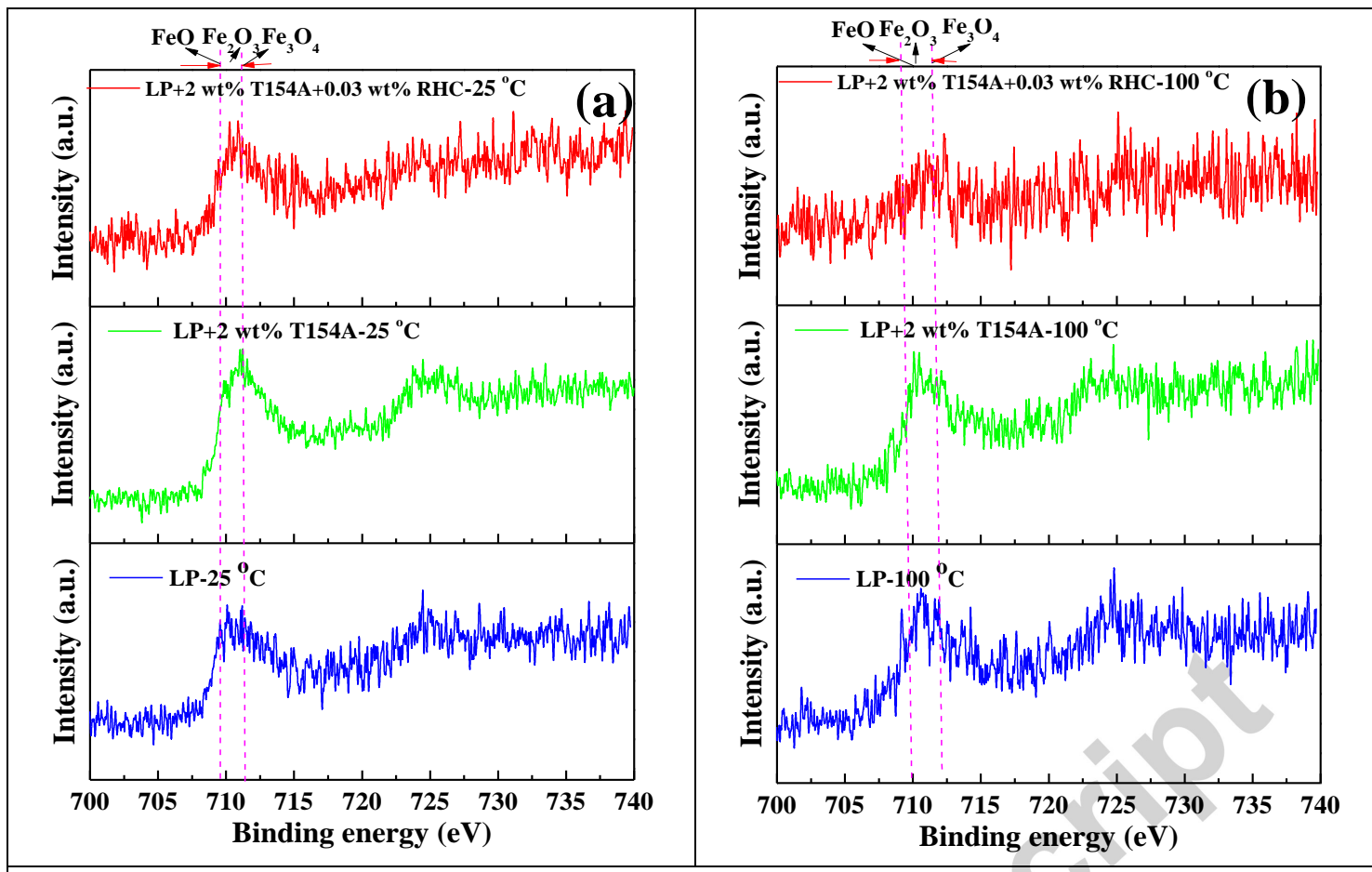

Figure 8 The $\mathrm{Fe}_{2 \mathrm{p}}$ spectra of worn traces lubricated with different oil samples (a) $25{ }^{\circ} \mathrm{C}$ (b) $100{ }^{\circ} \mathrm{C}$ 

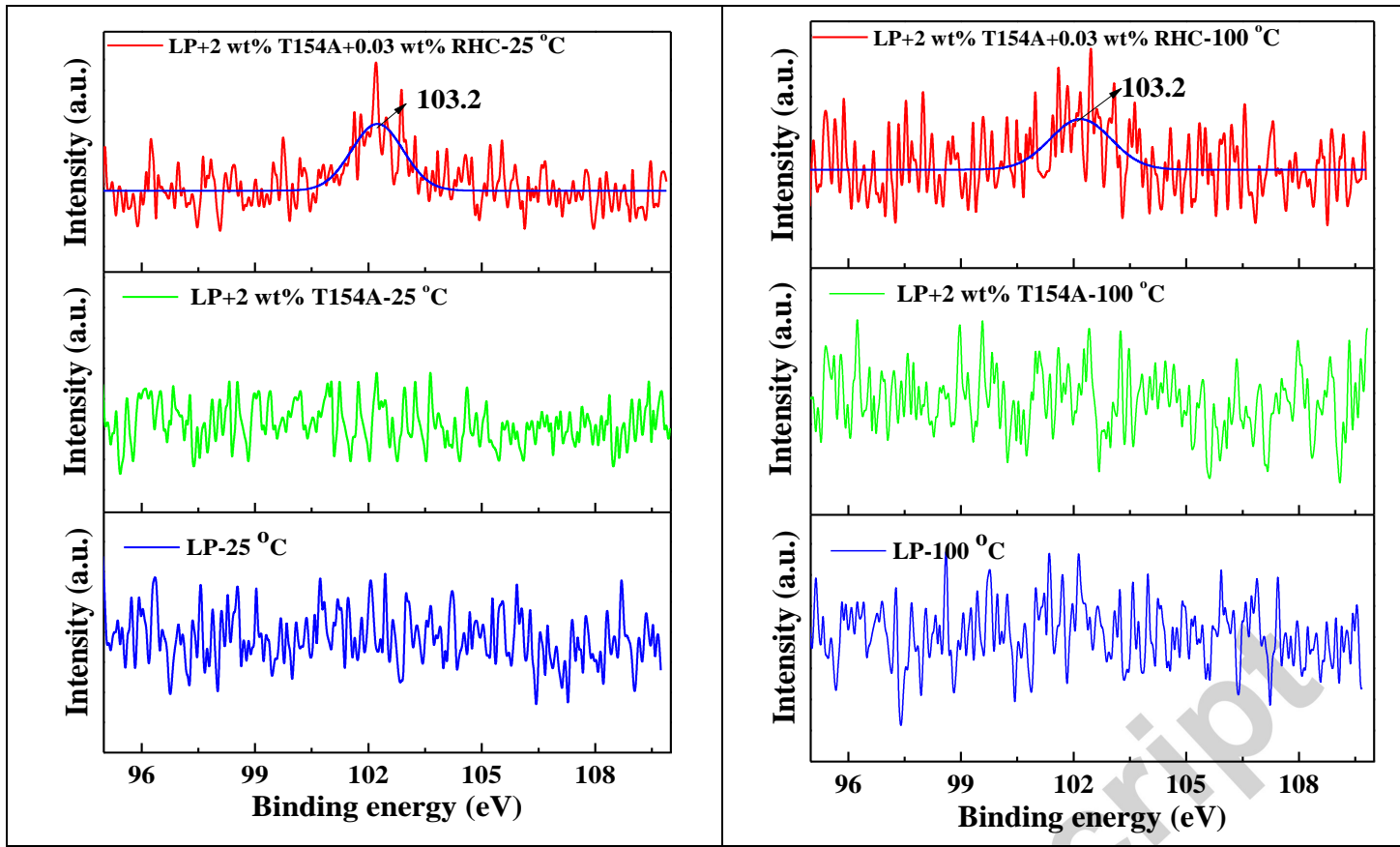

Figure 9 The $\mathrm{Si}_{2 p}$ spectra of worn traces lubricated with different oil samples (a) $25^{\circ} \mathrm{C}$ (b) $100{ }^{\circ} \mathrm{C}$ 

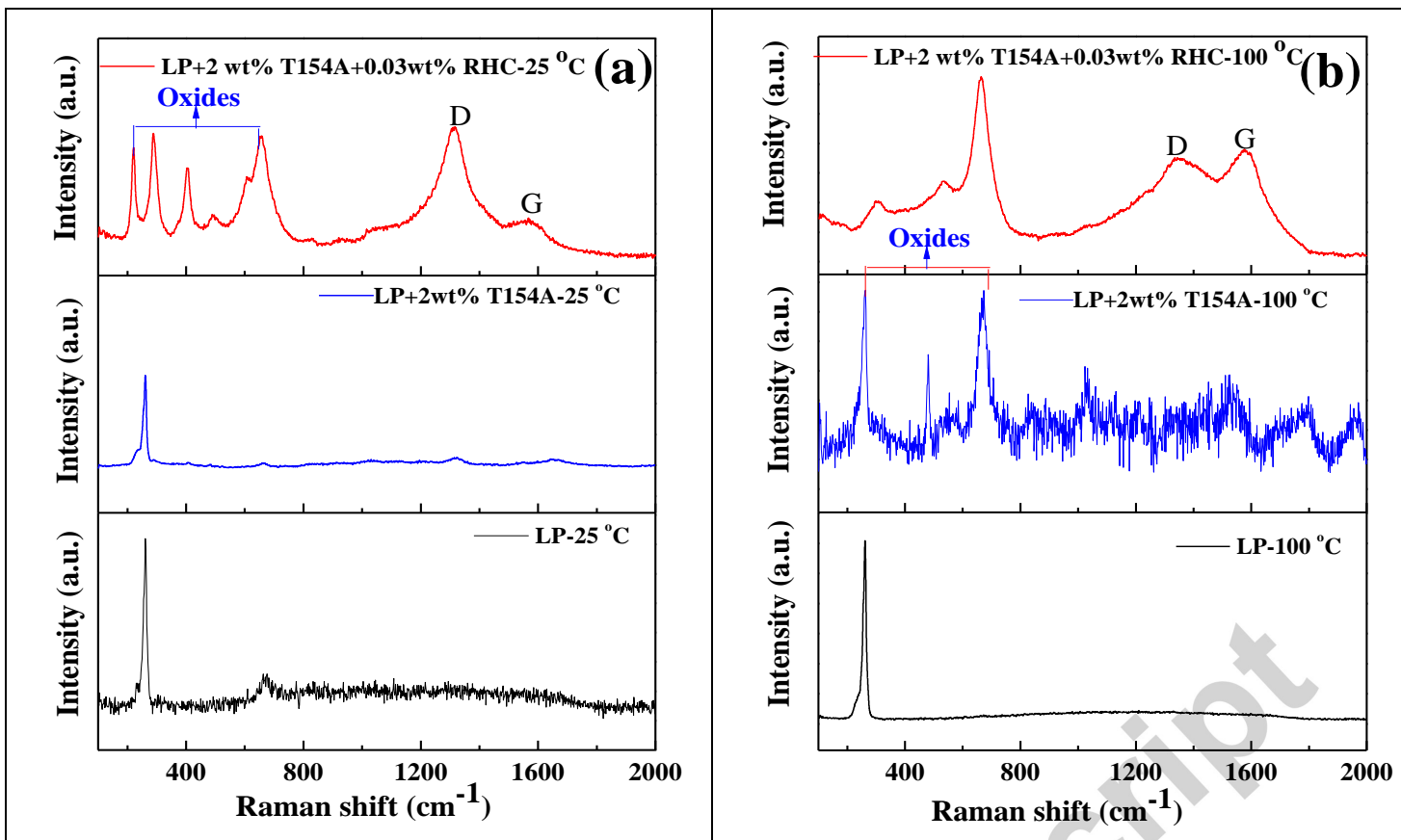

Figure 10 Raman analysis of worn traces lubricated with different oil samples 